\title{
Nonviral Vectors with a Biosurfactant MEL-A Promote Gene Transfection into Solid Tumors in the Mouse Abdominal Cavity
}

\author{
Yoshikazu Inoh, ${ }^{a}$ Tadahide Furuno ${ }^{a}$ Naohide Hirashima,,${ }^{b}$ and Mamoru NaKanishi ${ }^{*, a}$ \\ ${ }^{a}$ School of Pharmacy, Aichi Gakuin University; 1-100 Kusumoto-cho, Chikusa-ku, Nagoya 464-8650, Japan: and \\ ${ }^{b}$ Graduate School of Pharmaceutical Sciences, Nagoya City University; 3-1 Tanabe-dori, Mizuho-ku, Nagoya 467-8603, \\ Japan. Received June 23, 2008; accepted October 20, 2008; published online November 5, 2008
}

\begin{abstract}
Recently, we showed that a biosurfactatnt $4-O$ - $\left[\left(4^{\prime}, 6^{\prime}\right.\right.$-di- $O$-acethyl-2', $3^{\prime}$-di- $O$-alkanoyl)- $\beta$-D-mannopyranosyl] meso-erythritol A (MEL-A) greatly increased the efficiency of gene transfection mediated by cationic liposomes in vitro. We then studied whether the high transfection efficiency of these liposomes is maintained in vivo for tumor cells in the mouse abdominal cavity. When a complex of the liposomes and plasmid DNA was injected intraperitoneally into C57BL/6J mice bearing B16/BL6 tumors, we found that the biosurfactant significantly increased liposome-mediated gene transfection to the mouse tumor cells. The transfection efficiency of the plasmids into the solid tumors by the cationic liposomes of cholesteryl-3 $\beta$-carboxyamidoethylene- $N$-hydroxyethylamine (OH-Chol) with MEL-A increased by about 100-fold compared with that by the cationic liposomes of DCChol (commercially available) without MEL-A. The results suggest that nonviral vectors with MEL-A are very useful for gene transfection in vivo.
\end{abstract}

Key words nonviral vector; cationic liposome; biosurfactant; gene transfection

Gene transfection using nonviral vectors into cells is considered to be a promising method for gene therapy. ${ }^{1-3)}$ To develop the efficiency of gene transfection, several nonviral vectors have been investigated. ${ }^{4-7)}$ Lipofection using cationic liposomes is noted for its low toxicity and easy preparation. ${ }^{8,9)}$ In addition, we showed that cationic liposomes with a cholesterol derivative containing a hydrophilic amino head group, cholesteryl-3 $\beta$-carboxyamidoethylene- $N$ hydroxyethylamine (OH-Chol) and 1,2-dioleoyl-sn-glycero3-phosphatidylethanolamine (DOPE), achieved high transfection efficiency and low toxicity in vitro. ${ }^{10,11)}$ Furthermore, we showed that a biosurfactatnt $4-O-\left[\left(4^{\prime}, 6^{\prime}\right.\right.$-di- $O$-acethyl$2^{\prime}, 3^{\prime}$-di- $O$-alkanoyl)- $\beta$-D-mannopyranosyl] meso-erythritol A (MEL-A) markedly increased the efficiency of liposome-mediated gene transfection by cationic liposomes with $\mathrm{OH}-\mathrm{Chol}$ and DOPE in vitro. ${ }^{12)}$ The high transfection efficiency of MEL-A-containing cationic liposomes was found to be due to membrane fusion between the target cells and cationic liposomes. ${ }^{13,14)}$

For the in vivo application of nonviral vectors, many researchers have tried to identify vectors with high efficiency and safety, although the results are not yet satisfactory. ${ }^{15-18)}$ In the present experiments, we studied the in vivo gene transfection of MEL-A-containing cationic liposome/DNA complexes to solid tumors after regional administration. After liposome/DNA complexes were administrated intraperitoneally to $\mathrm{C} 57 \mathrm{BL} / 6 \mathrm{~J}$ mice with B16/BL6 tumor cells, the efficiency of gene transfection was measured based on the relative light unit (RLU) of chemiluminescence from products of plasmid DNAs (pRL-CMV).

\section{MATERIALS AND METHODS}

Materials The synthesis of a cationic cholesterol derivative, $\mathrm{OH}-\mathrm{Chol}$ was described in our previous paper. ${ }^{10)} \mathrm{DOPE}$ was purchased from Sigma (St. Louis, MO, U.S.A.). Luciferase plasmid (pRL-CMV) was purchased from Promega (Madison, WI, U.S.A.). MEL-producing yeast (Candida antarctica T-34) was isolated from the exudate of a tree on
Mt. Tsukuba, Japan. MEL-A was synthesized following the procedure described in a previous report. ${ }^{19)}$

Cell Culture B16/BL6 melanoma cells were cultured in Dulbecco's modified Eagle's medium (DMEM) from Gibco (Grand Island, NY, U.S.A.) supplemented with 10\% fetal bovine serum (Trace, Melbourne, Australia).

Preparation of Liposome/Plasmid DNA Complexes Cationic liposomes were prepared from DOPE $(30 \mathrm{nmol} /$ DNA $5 \mu \mathrm{g})$, DC-Chol $(20 \mathrm{nmol} / \mathrm{DNA} 5 \mu \mathrm{g})$, and MEL-A $(10 \mathrm{nmol} / \mathrm{DNA} 5 \mu \mathrm{g})$, or DOPE $(20 \mathrm{nmol} / \mathrm{DNA} 5 \mu \mathrm{g})$, OHChol $(30 \mathrm{nmol} / \mathrm{DNA} 5 \mu \mathrm{g})$, and MEL-A (10 nmol/DNA $5 \mu \mathrm{g})$ in chloroform and dried with $\mathrm{N}_{2}$ gas to remove the chloroform solvent, because this ratio of components in liposomeDNA complexes showed the maximum efficiency for gene transfection in vitro. ${ }^{12,13)}$ The mixtures were dried under reduced pressure to remove chloroform solvent. The lipid film was hydrated with $500 \mu$ l of phosphate buffered-saline (PBS) for $1 \mathrm{~h}$. The samples were sonicated in a bath-type sonicator (Branson model B 1200) to generate small unilamellar vesicles following our previous procedures. ${ }^{10,12-14)}$ Five hundred microliters of cationic liposomes were complexed with $25 \mu \mathrm{g}$ of plasmid pRL-CMV DNA according to the reported method. ${ }^{20)}$

Transfection Female C57BL/6J mice ( 6 to 7 weeks old) were used for all experiments. Experiments were performed according to the Guiding Principles for the Care and Use of Laboratory Animals approved by the Japanese Pharmacological Society.

Mice were injected intraperitoneally with $1 \times 10^{5}$ B16/BL6 murine tumor cells in $500 \mu \mathrm{l}$ of Hanks' balanced salt solution. The tumors were allowed to grow for $10 \mathrm{~d}$, and then the mice were intraperitoneally administered liposome/DNA complexes. After $24 \mathrm{~h}$, the solid tumors were collected and washed three times with PBS. The collected tumors are stored at $-20^{\circ} \mathrm{C}$ until luciferase assay. ${ }^{20)}$ Morphologic features of the tumors did not differ significantly among the mice used in the present experiments, as shown in Fig. 1.

Luciferase Assay The luciferase assay was carried out using a picagene luciferase assay kit (Toyo Ink, Tokyo, 


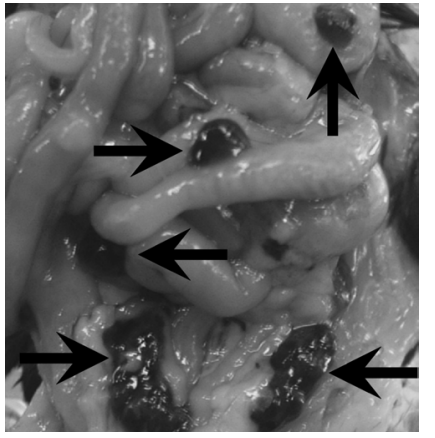

Fig. 1. B16/BL6 Solid Tumors in the Abdominal Cavity of C57BL/6J Mice

C57BL/6J mice were injected intraperitoneally with B16/BL6 tumor cells, and $10 \mathrm{~d}$ later the solid melanoma tumors (arrows) formed.

Japan). The transfected cells were washed three times with PBS and lysed in a cell lysis buffer. The lysate was centrifuged at $12000 \times \boldsymbol{g}$ at $4{ }^{\circ} \mathrm{C}$ for $3 \mathrm{~min}$, and the supernatant was subjected to the luciferase assay. The RLU of chemiluminescence was measured with a luminometer (TD-20/20; Turner Designs; Sunnyvale, CA, U.S.A.) and the luminescent RLU values were normalized to the amounts of total protein determined in the bicinchoninic acid (BCA) assay. ${ }^{12-14)}$

\section{RESULTS}

To study the in vivo gene transfection efficiency of intraperitoneally administered cationic liposomes with and without the biosurfactant, we used the murine B16/BL6 solid tumor model. ${ }^{20)} \mathrm{B} 16 / \mathrm{BL} 6$ tumor cells were injected intraperitoneally into C57BL/6J mice and allowed to grow. After $10 \mathrm{~d}$, the B16/BL6 solid tumors formed in the abdominal cavity of C57BL/6J mice, as shown in Fig. 1.

We prepared two types of cationic liposomes to compare in vivo gene ( $\mathrm{pRL}-\mathrm{CMV}$ DNA) transfection efficiencies in $\mathrm{C} 57 \mathrm{BL} / 6 \mathrm{~J}$ mice bearing B16/BL6 tumors. One is a liposome made of DOPE and DC-Chol (commercially available) and the other is composed of DOPE and OH-Chol, as described above. The complexes of liposomes and plasmid pRL-CMV DNA $(25 \mu \mathrm{g})$ were injected intraperitoneally into $\mathrm{C} 57 \mathrm{BL} / 6 \mathrm{~J}$ mice bearing B16/BL6 tumors. The tumors were collected $24 \mathrm{~h}$ after administration, and the gene transfection efficiency was measured in the luciferase assay. The white column in Fig. 2a shows the transfection efficiency of DC-Chol liposomes $\left(1.5 \times 10^{6} \mathrm{RLU} / \mathrm{mg}\right.$ protein $)$ and the gray column that of $\mathrm{OH}-\mathrm{Chol}$ liposomes $\left(4.9 \times 10^{7} \mathrm{RLU} / \mathrm{mg}\right.$ protein). The transfection efficiency to intraperitoneal solid tumors of the $\mathrm{OH}-\mathrm{Chol}$ liposomes is much greater than that of the DCChol liposomes. The naked plasmid pRL-CMV DNA (plasmid alone) showed negligible transfection activity.

Next, we studied the effects of the biosurfactant MEL-A on in vivo gene transfection efficiency using the two types of cationic liposomes. The gene transfection activities in solid tumors mediated by the cationic liposomes with MEL-A are shown in Fig. 2b, where the white column shows the transfection efficiency of DC-Chol liposomes $\left(9.7 \times 10^{6} \mathrm{RLU} / \mathrm{mg}\right.$ protein) and the gray column that of $\mathrm{OH}-\mathrm{Chol}$ liposomes $\left(14.2 \times 10^{7} \mathrm{RLU} / \mathrm{mg}\right.$ protein). The results show that the biosurfactant significantly increased the gene transfection efficiency to the solid tumors in the mouse abdominal cavity (a)

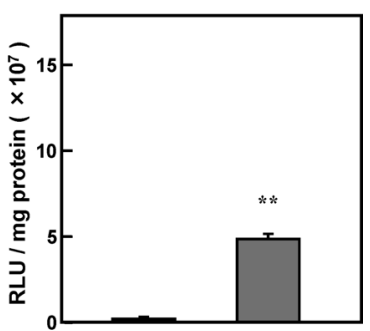

(b)

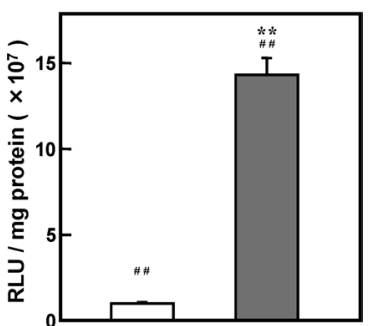

Fig. 2. Transfection Efficiency to Solid Tumors Mediated by Cationic Liposomes

Mice bearing B16/BL6 solid tumors in the abdominal cavity were injected intraperitoneally with liposome/DNA complexes. After $24 \mathrm{~h}$, the tumors were collected, washed three times with PBS, and transfection efficiency measured in the luciferase assay. (a) In vivo transfection efficiency using cationic liposomes composed of cholesterol derivatives OH-Chol (gray bar) or DC-Chol (white bar). (b) Effects of a biosurfactant (MELA) on in vivo gene transfection efficiency using cationic liposomes composed of $\mathrm{OH}$ Chol (gray bar) or DC-Chol (white bar). Values are mean \pm S.E. $(n=3$ animals) $* * p<0.01$ compared with values of liposomes composed of DC-Chol. \# $p<0.01 \mathrm{com}-$ pared with value.

with both types of cationic liposome (Fig. 2). We also found that $\mathrm{OH}-\mathrm{Chol}$ liposomes with the biosurfactant had the highest gene transfection efficiency in vivo among liposomes described here.

\section{DISCUSSION}

Biosurfactants are extracellular amphiphilic compounds produced by microorganisms and have attracted considerable interest because of their biodegradability, ease of production, and other functions. The numerous advantages of biosurfactants have promoted applications in the food, cosmetic, and pharmaceutical industries, and environmental protection and energy-saving technology. In addition, biosurfactants play important roles as immunoregulators and immunomodulators in adhesion and desorption in cellular systems.

MEL-A is a glycolipid biosurfactant composed of both lipophilic and hydrophilic moieties. We showed that MEL-Acontaining cationic liposomes markedly promoted the efficiency of gene transfection into mammalian cultured cells in vitro. ${ }^{12-14)}$ However, it was unclear whether the cationic liposomes with biosurfactants would be useful for gene transfection in vivo. In the present experiment, we intraperitoneally administered cationic liposome/DNA complexes to mice bearing B16/BL6 solid tumors. We found that the transfection efficiency to intraperitoneal solid tumors by $\mathrm{OH}-\mathrm{Chol}$ liposomes was higher than that of the DC-Chol liposomes. In addition, the biosurfactant MEL-A greatly increased the transfection efficiencies of both liposomes. The gene transfection efficiency into solid tumors by $\mathrm{OH}-\mathrm{Chol}$ liposomes with MEL-A increased by about 100 -fold compared with that by DC-Chol liposomes without MEL-A. These results sug- 
gest that MEL-A promotes the efficiency not only in in vitro but also in vivo gene transfection. Nonviral vectors with biosurfactants are thus useful tools for gene transfection and gene therapy.

Acknowledgment We thank Dr. Dai Kitamoto (National Institute of Advanced Industrial Science and Technology, Tsukuba, Japan) for the use of MEL-A.

\section{REFERENCES}

1) Felgner P. L., Ringold G. M., Nature (London), 337, 387-388 (1995).

2) Felgner P. L., Gadek T. R., Holm M., Roman R., Chan H. W., Wenz M., Northrop J. P., Ringold G. M., Danielsen M., Proc. Natl. Acad. Sci. U.S.A., 84, 7413-7417 (1987).

3) Gao X., Huang L., Biochem. Biophys. Res. Commun., 179, 280-285 (1991).

4) Zhou X., Huang L., Biochim. Biophys. Acta, 1189, 195-203 (1994).

5) Fujiwara T., Hasegawa S., Hirashima N., Nakanishi M., Ohwada T., Biochim. Biophys. Acta, 1468, 396-402 (2000).

6) Nishiyama N., Iriyama A., Jang W. D., Miyata K., Itaka K., Inoue Y., Takahashi H., Yanagi Y., Tamaki Y., Koyama Y., Kataoka K., Nat. Mater., 4, 934-941 (2005).

7) Hatakeyama H., Akita H., Kogure K., Oishi M., Nagasaki Y., Kihira
Y., Ueno M., Kobayashi H., Kikuchi H., Harashima H., Gene Ther. 14, 68-77 (2007)

8) Farhood H., Bottega R., Epand R. M., Huang L., Biochem. Biophys. Res. Commun., 1111, 239-246 (1992).

9) Lasic D. D., Trends Biotechnol., 16, 307-321 (1998).

10) Okayama R., Noji M., Nakanishi M., FEBS Lett., 408, 232-234 (1997).

11) Nakanishi M., Curr. Med. Chem., 10, 1289-1296 (2003).

12) Inoh Y., Kitamoto D., Hirashima N., Nakanishi M., Biochem. Biophys. Res. Commun., 289, 57-61 (2001).

13) Inoh Y., Kitamoto D., Hirashima N., Nakanishi M., J. Controlled Release, 94, 423-431 (2004).

14) Ueno Y., Inoh Y., Furuno T., Hirashima N., Kitamoto D., Nakanishi M., J. Controlled Release, 123, 247-253 (2007).

15) Li S., Huang L., Gene Ther., 7, 31-34 (2000).

16) Fletcher S., Ahmad A., Perouzel E., Heron A., Miller A. D., Jorgensen M. R., J. Med. Chem., 49, 349-357 (2006).

17) Wu J., Lee A., Lu Y., Lee R. J., Int. J. Pharm., 337, 329-335 (2007).

18) Suzuki R., Takizawa T., Negishi Y., Utoguchi N., Sawamura K., Tanaka K., Namai E., Oda Y., Matsumura Y., Maruyama K., J. Controlled Release, 125, 137-144 (2008)

19) Kitamoto D., Akiba S., Hioki T., Tabuchi T., Agric. Biol. Chem., 54, 31-36 (1990).

20) Reimer D. L., Kong S., Monck M., Wyles J., Tam P., Wassan E. K., Bally M. B., J. Pharmacol. Exp. Ther, 289, 807-815 (1999). 